\title{
Warfarin and acetaminophen interaction in a 47-year-old woman
}

\author{
Derek Leong RPh BScPhm, Peter E. Wu MD MSc
}

Cite as: CMAJ 2020 May 11;192:E506-8. doi: 10.1503/cmaj.191532

A 47-year-old woman presented to hospital with a 2-day history of pain and bruising in her left upper back. She had a medical history of rheumatic heart disease with a mechanical mitral valve replacement. Her only prescription medication was warfarin, targeting an international normalized ratio (INR) of 2.5-3.5. For the past 12 months, the patient's warfarin dosage had remained unchanged, with a relatively wellcontrolled INR between 2.1 and 3.7. One week earlier, she had gone to a walk-in clinic because of musculoskeletal leg pain and was instructed to use only acetaminophen. For 7 days before presentation, she had taken 500-1000 mg every 4 hours with a total daily dose of $2500-4000 \mathrm{mg}$. The patient was not taking any other over-the-counter medications or supplements. There was no history of traumatic injury. On examination, the patient appeared unwell. There was diffuse ecchymosis, swelling and warmth surrounding her left upper back. Her temperature was $36.6^{\circ} \mathrm{C}$, blood pressure was $122 / 70 \mathrm{~mm} \mathrm{Hg}$, pulse was 110 beats/ $\mathrm{min}$, respiratory rate was 22 breaths/min and she was saturating $99 \%$ on room air. Her laboratory measurements (Table 1 ) showed a drop in hemoglobin levels from $126 \mathrm{~g} / \mathrm{L}$ at baseline to $101 \mathrm{~g} / \mathrm{L}$ on initial emergency assessment and then, 16 hours later, to $78 \mathrm{~g} / \mathrm{L}$. Her INR was initially reported as "> 5.0," but then was reported as 9.2 on a repeat measurement. Computed tomography of the thorax showed a large left oblique intramuscular hematoma with features of active bleeding.

Given the acuity of her presentation and the supratherapeutic INR with active bleeding, and in consultation with the hematology service, blood bank, and cardiovascular and thoracic surgery, the warfarin was held and reversed with 3000 units of prothrombin complex concentrate plus $10 \mathrm{mg}$ of intravenous vitamin $\mathrm{K}$, and she was given 1 unit of packed red blood cells. Repeat INR and hemoglobin measurements were 0.9 and $91 \mathrm{~g} / \mathrm{L}$, respectively. The patient was started on intravenous unfractionated heparin (initial infusion rate 18 units $/ \mathrm{kg} / \mathrm{h}$ with adjustments as per nomogram; no bolus) to maintain therapeutic anticoagulation for her mechanical valve. The heparin infusion was felt to be the safest option for anticoagulation in the setting of major bleeding given heparin's short half-life and the option to reverse, if needed, with protamine.

After 7 days of observation, the patient's hemoglobin levels remained stable, without any further transfusion requirements.

\section{KEY POINTS}

- Acetaminophen can increase a patient's international normalized ratio (INR) in a dose-dependent manner.

- Concomitant use of acetaminophen and warfarin can result in a pharmacodynamic interaction leading to a supratherapeutic INR and consequent bleeding.

- Patients taking warfarin who are at high risk of bleeding require close INR monitoring when starting and stopping courses of acetaminophen.

- Management involves cessation of acetaminophen exposure and reversal of the effects of warfarin in the setting of clinically important bleeding.

Over the next week, she was bridged back to warfarin and subsequently discharged home with an INR of 2.5 and a hemoglobin level of $99 \mathrm{~g} / \mathrm{L}$. The patient's back pain and initial musculoskeletal leg pain resolved with time and physiotherapy, and she did not require any further analgesia.

The only new medication that had been introduced was the acetaminophen, and given the temporal relation, the diagnosis was an adverse drug-drug interaction between warfarin and acetaminophen resulting in a supratherapeutic INR and consequent bleeding.

\section{Discussion}

This case describes an adverse drug-drug interaction between acetaminophen and warfarin resulting in a potentially lifethreatening bleed in a patient who needed anticoagulation because of a mechanical valve. Warfarin is a medication that requires careful monitoring and titration, as its effects are subject to individual genetic factors, physiologic and age-related changes, and pharmacodynamic and pharmacokinetic interactions with food and drugs. ${ }^{1}$ Even though acetaminophen can interact with warfarin, these 2 medications are commonly coprescribed. ${ }^{2-4}$ It is generally recommended that patients taking warfarin avoid nonsteroidal anti-inflammatory drugs owing to increased bleeding risk, leaving acetaminophen as the only analgesic or antipyretic option. ${ }^{1}$ A US retrospective cohort study involving 134833 patients taking warfarin found that $18.5 \%$ of these patients were also prescribed 
Table 1: Trend of laboratory measurements in a 47-year-old woman with warfarin and acetaminophen interaction

\begin{tabular}{|c|c|c|}
\hline Timeline & INR & $\begin{array}{l}\text { Hemoglobin, } \\
\text { g/L }\end{array}$ \\
\hline 2 months before admission & 2.5 & 126 \\
\hline Day 1 (on presentation) & $>5.0$ & 101 \\
\hline Day 2 (16 h postadmission) & 9.2 & 78 \\
\hline $\begin{array}{l}\text { Day } 2 \text { ( } 20 \mathrm{~h} \text { postadmission, } 2 \mathrm{~h} \text { after } \\
\text { warfarin reversal) }\end{array}$ & 0.9 & NA \\
\hline $\begin{array}{l}\text { Day } 2 \text { ( } 24 \mathrm{~h} \text { postadmission, } 6 \mathrm{~h} \text { after PRBC } \\
\text { transfusion) }\end{array}$ & NA & 91 \\
\hline Day 3 (morning) & 1.2 & 83 \\
\hline Day 3 (evening) & 1.0 & 77 \\
\hline Day 4 & 1.3 & 75 \\
\hline Day 5 & 1.2 & 71 \\
\hline Day 6 & 1.2 & 74 \\
\hline Day 7 & 1.2 & 74 \\
\hline Day 8 (warfarin restarted) & 1.1 & 76 \\
\hline Day 10 & 1.2 & 89 \\
\hline Day 11 & 1.4 & 97 \\
\hline Day 12 & 1.8 & 91 \\
\hline Day 13 & 1.9 & NA \\
\hline Day 14 & 2.1 & NA \\
\hline Day 15 & 2.3 & 99 \\
\hline Day 16 & 2.5 & NA \\
\hline
\end{tabular}

acetaminophen, though the actual percentage is likely higher given that this did not include acetaminophen obtained over the counter. ${ }^{5} \mathrm{~A}$ case-control study involving 93 patients suggested that acetaminophen was a significant risk factor for excess warfarin anticoagulation, with as high as a 10-fold increased risk of having an INR greater than 6.0. ${ }^{6} \mathrm{~A}$ systematic review and meta-analysis of 7 randomized controlled trials (RCTs) looking at mean differences of maximum INR change when comparing acetaminophen $(1.3-4 \mathrm{~g} / \mathrm{d})$ with placebo in patients taking vitamin $\mathrm{K}$ antagonists found that acetaminophen caused a dose-dependent increase in the INR of 0.17 per gram per day, with an average INR increase of 0.62. ${ }^{2}$ The duration of concomitant warfarin and acetaminophen use ranged from 10 days to 6 weeks. ${ }^{2}$ Importantly, trials withdrew patients for safety reasons if their INR deviated too far from target (e.g., > 3.3 or 3.5), thus underestimating the severity of INR increase if acetaminophen use had been continued. ${ }^{2}$

Acetaminophen does not interfere with warfarin metabolism or clearance but rather leads to a pharmacodynamic interaction whereby the combined effects synergistically affect coagulation and increase INR (Figure 1). The mechanism is due to the oxidative effects of the acetaminophen metabolite $\mathrm{N}$-acetyl-pbenzoquinone-imine (NAPQI) on several steps of the vitamin $\mathrm{K}$ cycle. ${ }^{3,4} \mathrm{NAPQI}$, the reactive intermediate responsible for hepatic injury in acetaminophen toxicity, is metabolized from acetaminophen by the cytochrome P450 (CYP) isoform 2E1. NAPQI is normally detoxified by glutathione into cysteine and mercapturic acid conjugates. ${ }^{7} \mathrm{NAPQI}$ can accumulate for a variety of reasons, including glutathione depletion, acetaminophen excess or induction of CYP2E1 (e.g., secondary to chronic alcohol use, or due to CYP450 inducers such as rifampin or phenytoin). ${ }^{8}$ NAPQI interferes with the vitamin $\mathrm{K}$ cycle by inhibiting vitamin $\mathrm{K}$ dependent carboxylase and vitamin $\mathrm{K}$ epoxide reductase via oxidation of sulfhydryl groups and cysteine groups, respectively, and oxidizes vitamin $\mathrm{K}$ hydroquinone (the reduced form of vitamin K), thus decreasing available substrate for vitamin Kdependent carboxylase. These combined effects of NAPQI and warfarin cause a more pronounced depletion of activated vitamin $\mathrm{K}$-dependent clotting factors, resulting in an elevated INR and risk of bleeding. ${ }^{1,3,4}$ Individual genetic variations in the activity of all of these enzymes challenge the predictability of response to warfarin and susceptibility to interactions. ${ }^{1}$

There are currently no prospective RCTs to guide management in patients taking warfarin who require concurrent acetaminophen; ${ }^{3}$ therefore, treatment recommendations are based primarily on expert opinion. Patients taking warfarin should be advised to speak with their primary care provider and pharmacist before starting any new medications, including over-thecounter medications containing acetaminophen. ${ }^{9}$ Generally, the dose and duration of acetaminophen should be limited to the lowest dose and shortest duration possible. For a patient who is stabilized on warfarin, close INR monitoring is prudent if acetaminophen use at moderate to high doses (2-4 g/d) for a prolonged period is anticipated, with dose adjustments to warfarin made where appropriate. ${ }^{1,3,9}$ Some authorities recommend checking the INR around 3-5 days after the first dose of acetaminophen in those taking at least $2 \mathrm{~g} / \mathrm{d}$ for at least 3 consecutive days. ${ }^{3}$ However, closer monitoring would be warranted in patients at high risk of INR fluctuations (e.g., older patients and patients taking interacting medications) or who are at high risk of bleeding (e.g., patients with a prior history of bleeding events and patients with a higher INR target of 2.5-3.5). ${ }^{9}$ Likewise, once acetaminophen is no longer indicated and discontinued, the INR will need to be followed closely, as a decrease in INR within several days is expected, potentially becoming subtherapeutic. ${ }^{9}$ In patients with bleeding complications in the setting of a supratherapeutic INR, warfarin should be interrupted and reversed as indicated with intravenous vitamin $\mathrm{K}$ and prothrombin complex concentrate, in addition to meticulous supportive care. ${ }^{1}$

Concomitant use of acetaminophen and warfarin is common, and the potential bleeding risk as a result of a drug-drug interaction may not be appreciated. Given that this is a dose-dependent interaction, higher doses of acetaminophen over prolonged periods will place patients at greater risk. Close monitoring is required when initiating and stopping acetaminophen. There are no studies to guide when patients should have their INR checked, but the consequences of severe bleeding should be weighed against the inconvenience of more frequent INR checks, with increased monitoring warranted in those at higher risk, such as in our patient with a mechanical valve. 


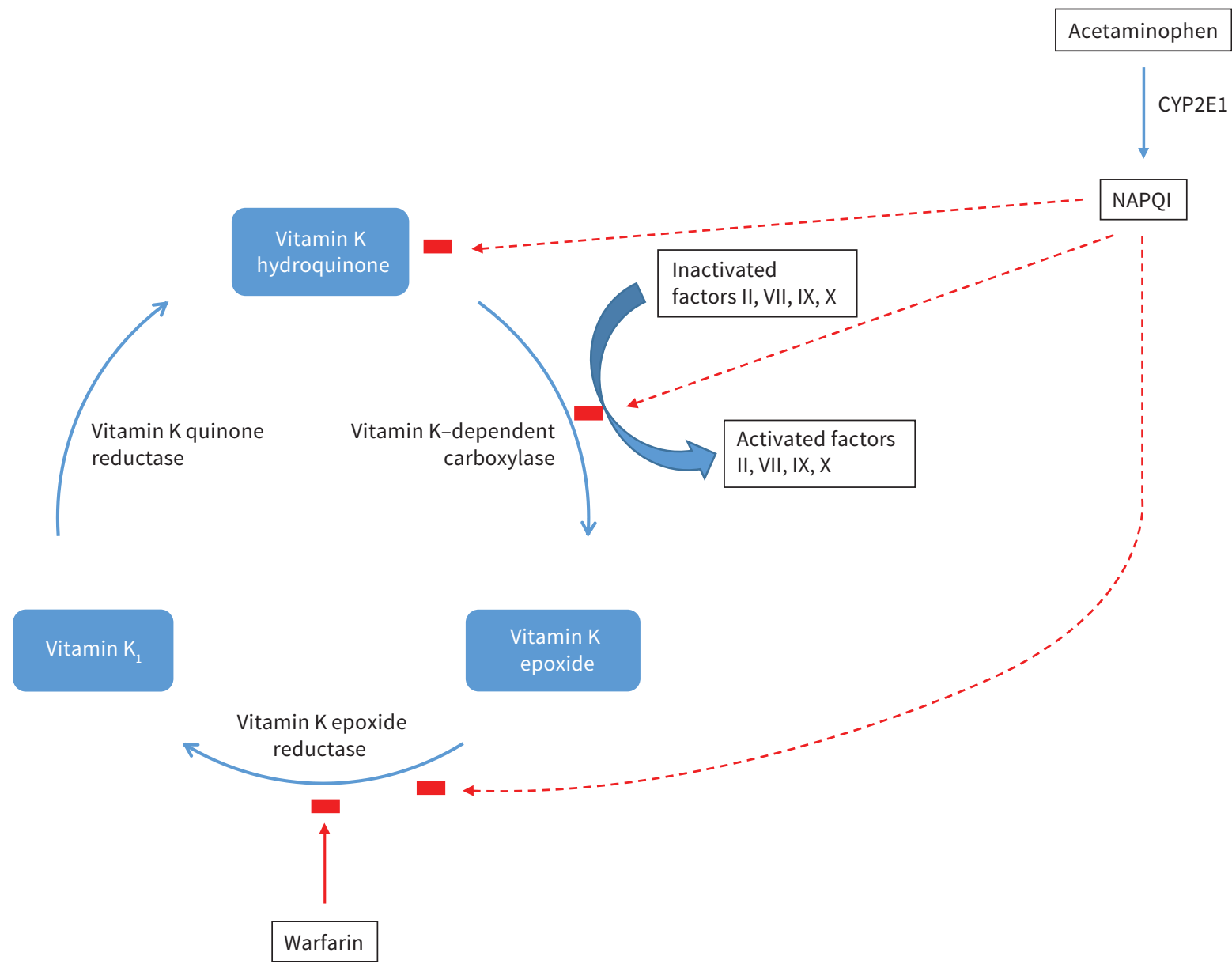

Figure 1: Acetaminophen is metabolized by CYP2E1 to $\mathrm{N}$-acetyl-p-benzoquinone-imine (NAPQI), which interferes with several steps in the vitamin $\mathrm{K}$ cycle, while warfarin inhibits vitamin $\mathrm{K}$ epoxide reductase. The combined effects result in a pharmacodynamic interaction that increases a patient's international normalized ratio., ${ }^{3,4}$

\section{References}

1. Ageno W, Gallus AS, Wittkowsky A, et al. Oral anticoagulant therapy: Antithrombotic Therapy and Prevention of Thrombosis, 9th ed: American College of Chest Physicians Evidence-Based Clinical Practice Guidelines. Chest 2012;141(Suppl):e44S-88S.

2. Caldeira D, Costa J, Barra M, et al. How safe is acetaminophen use in patients treated with vitamin $\mathrm{K}$ antagonists? A systematic review and meta-analysis. Thromb Res 2015;135:58-61.

3. Lopes RD, Horowitz JD, Garcia DA, et al. Warfarin and acetaminophen interaction: a summary of the evidence and biologic plausibility. Blood 2011;118:6269-73.

4. Thijssen HH, Soute BA, Vervoort LM, et al. Paracetamol (acetaminophen) warfarin interaction: NAPQI, the toxic metabolite of paracetamol, is an inhibitor of enzymes in the vitamin K cycle. Thromb Haemost 2004;92:797-802.

5. Wittkowsky AK, Boccuzzi SJ, Wogen J, et al. Frequency of concurrent use of warfarin with potentially interacting drugs. Pharmacotherapy 2004;24:1668-74.

6. Hylek EM, Heiman $\mathrm{H}$, Skates SJ, et al. Acetaminophen and other risk factors for excessive warfarin anticoagulation. JAMA 1998;279:657-62.

7. Heard KJ. Acetylcysteine for acetaminophen poisoning. N Engl J Med 2008; 359:285-92.

8. Ferner RE, Dear JW, Bateman DN. Management of paracetamol poisoning. BMJ 2011;342:d2218.

9. Hughes GJ, Patel PN, Saxena N. Effect of acetaminophen on international normalized ratio in patients receiving warfarin therapy. Pharmacotherapy 2011; 31:591-7.

\section{Competing interests: None declared.}

This article has been peer reviewed.

The authors have obtained patient consent.

Affiliations: Department of Pharmacy (Leong) and Division of General Internal Medicine and
Geriatrics (Wu), University Health Network; Division of Clinical Pharmacology and Toxicology $(\mathrm{Wu})$, Department of Medicine, University of Toronto, Toronto, Ont.

Contributors: Both authors contributed to the conception and design of the work, drafted the work and revised it critically for important intellectual content, gave final approval of the version to be published and agreed to be accountable for all aspects of the work.

Correspondence to: Derek Leong, derek.leong@uhn.ca 